\title{
Development of Digestive System Video for Learning Anatomy in Pandemic Era
}

\author{
Nanang Wiyono ${ }^{1 *}$, Siti Munawaroh ${ }^{1}$, Yunia Hastami $^{1}$, Selfi Handayani ${ }^{1}$, \\ Dhoni Akbar Ghozali ${ }^{1}$, Muthmainah ${ }^{1}$
}

${ }^{1}$ Department of Anatomy, Faculty of Medicine, Universitas Sebelas Maret, Surakarta, Indonesia

*Corresponding author: nanang.wiyono@gmail.com

\begin{abstract}
Background and aims: The coronavirus disease 2019 (COVID-19) pandemic has had tremendous effects on medical education including anatomy. In pandemic conditions students cannot study with cadavers which has been known as "gold standard" for anatomy learning. Alternatives anatomy learning media are pursued, one of which is using anatomy video. This research aims to develop anatomy video for anatomy system and using them.

Methods: We utilize a consumer camera to record anatomy educational video in the laboratory setting using plastinated specimens., and then prepare them to play on Youtube. The process of creating content includes storyline creation, preparation of anatomy specimens for system, setting an anatomy laboratory, video recording, editing and publishing on Youtube Channel. Students the questions about utilize the videos

Results: The results show that these videos are appropriate material for an alternative educational media in learning anatomy in the pandemic era and future, although there are still some weaknesses found in these video. can acces video anytime and anywhere so they can study anatomy freely and more flexibly.

Conclusions: Anatomy video of digestive system helps students for learning anatomy in pandemic era and future.
\end{abstract}

Keywords: Anatomy, Video, Pandemic era.

\section{INTRODUCTION}

At the beginning of December 2019 in Wuhan, the capital city of Hubei, China, there was the first found unknown case of pneumonia with unknown cause that has been named Severe Acute Respiratory Syndrome Coronavirus 2 (SARS-CoV-2. The World Health Organization (WHO) declared SARS-CoV-2 as a pandemic on the $30^{\text {th }}$ of January 2020 and naming it officially COVID-19 on the 11th of February 2020. Indonesia reported its first and second cases on March 2nd, 2020. This pandemic has affected almost all sectors ranging from financial and investment business to aviation, tourism, hotels, restaurants, shipping, and the education sector [1][2]. The COVID-19 pandemic has disrupted and challenged the well-established of both undergraduate and graduate medical education [3] and caused disruption to the medical education process and to healthcare systems worldwide. It is difficult to continue lectures and laboratory learning because of the highly contagious nature of the virus, thus influencing the medical education process [4] including anatomy education.

Anatomy is considered as a basic science for medical and health students. It has been for a long time we used cadaver as "gold standard" for studying anatomy [5][6]. The COVID-19 pandemic affected unpredictable disruption to anatomical education practice as the medical students lost access to cadavers and a number of other learning modalities like models and plastination specimens due to lockdown [2]. The digital change is the option at present for anatomists and medical students.

The way in which anatomy is taught and the resources available to aid the delivery of material has evolved significantly for the last several decades. The modalities are anatomy mobile application with virtual and augmented reality technology and one of these resources has been videos. These modalities in anatomy education have transformed over this time due to technological advancements, flexibilities, many advantages, and curricula reform [7].

There are many materials can be used as teaching and learning media such as anatomy atlas, textbooks, videos and mobile application. The most important thing is that the material can be used by teacher and student to facilitate teaching and learning process. Alternatives anatomy learning media are pursued, one of which is using anatomy video. This research aims to 
develop anatomy video for anatomy system and using them.
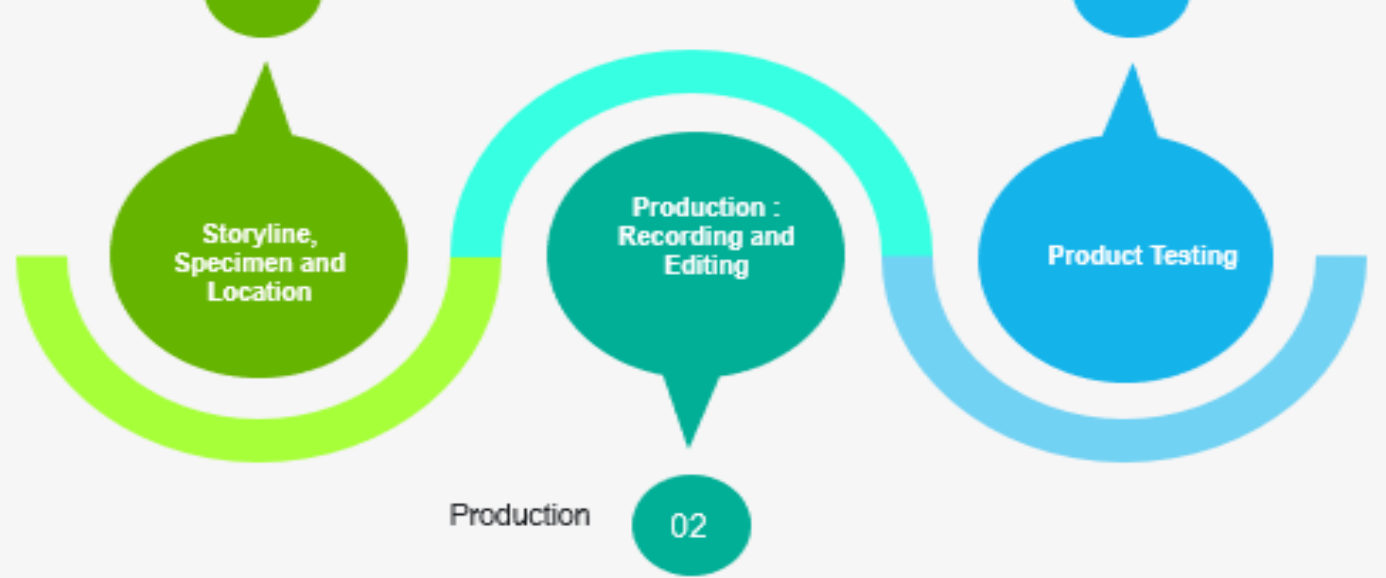

Figure 1 : Production processes of videos anatomy of digestive system

\section{METHODS}

The first stage of video creation begins with identifying anatomy of digestive system material in accordance with the textbook of anatomy and the standard book of Indonesian Anatomist Association for national anatomical curriculum. Anatomy of digestive system material consists of gastrointestinal tract including cavitas oris, esophagus, gaster, intestine tenue anda intestine crissum and the accessories organ of digestive system including dentes, lingua, salivary glands, hepar, vesica fellea and pancreas and also abdominal cavity. We used plastinated specimens in our laboratory for video material. After the material is determined it's continued making storyline for the video using appropriate preparations, laboratory settings and time allocation required. The next stage was video capture using the camera video by the crew in the
Anatomy Laboratory of Faculty of Medicine Universitas Sebelas Maret Surakarta. Video shooting were done according to the storyline with a time of about 2-5 minutes per scene. The videos were stored in the video camera memory. After videos were recorded with the camera, they must then be imported into computer into compute and exported it as a standard MP4 file to be edited by any standard video editor. Videos that have been validated are uploaded in Youtube channels the number of ethical clearance for this research is 185/II/HREC/2021

\section{RESULTS}

Anatomy videos of the digestive system uploaded in Youtube channel so students can access the video every time and everywhere during the anatomical block of digestive system for about about one month.

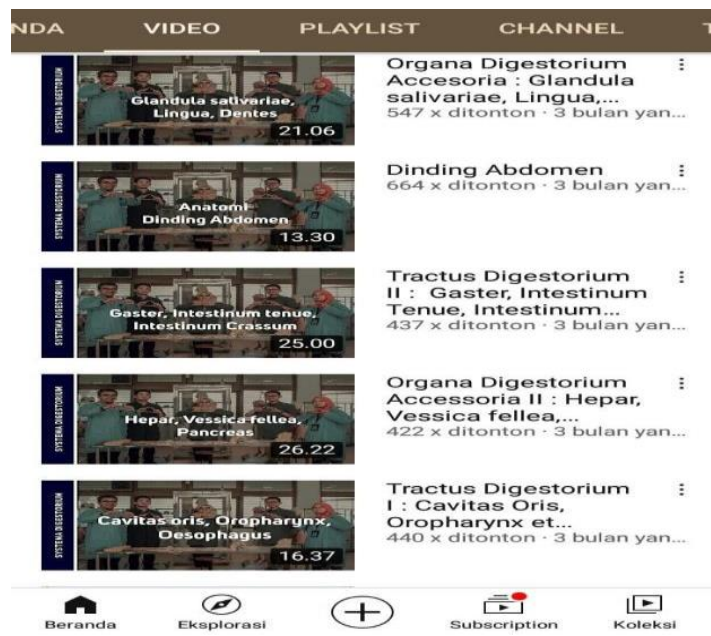

Figure 2. Videos anatomy of digestive system on Youtube channel 
After anatomical learning was completed students filled the survey questions. Data for the evaluation were collected using a survey of 191 medical students in the Faculty of Medicine Universitas Sebelas Maret. The survey was conducted by distributing the questionnaires to the users after they watched the videos. The results obtained from the questionnaires will be used for the evaluation of the videos.
The researchers evaluated the results of the survey which employed the attitude questionnaire using Likert Scale : $1=$ very disagree, $2=$ disagree, $3=$ netral, $4=$ agree and 5 = very agree

The results of Videos evaluation analysis are presented in Table 1.

Table 1. Evaluation results of videos anatomy of digestive system $(n=191)$

\begin{tabular}{|c|l|c|}
\hline Number & \multicolumn{1}{|c|}{ Question } & Mean score \\
\hline $\mathbf{1}$ & The condition of the Covid 19 pandemic made me feel difficulty learning anatomy & 4.20 \\
\hline $\mathbf{2}$ & I want to carry out practicum in anatomy laboratory & 4.69 \\
\hline $\mathbf{3}$ & I saw a video of anatomy learning systema digestorium directly on youtube & 4.25 \\
\hline $\mathbf{4}$ & I can learn anatomy of systema digestorium anytime and anywhere & 4.14 \\
\hline $\mathbf{5}$ & The display of anatomical learning video systema digestorium has been good & 4.24 \\
\hline $\mathbf{6}$ & Image quality video anatomy systema digestorium is good & 4.52 \\
\hline $\mathbf{7}$ & The sound quality of the anatomy learning video systema digestorium has been good & 4.02 \\
\hline $\mathbf{8}$ & I can clearly see the anatomical structure referred to in the video & 4.01 \\
\hline $\mathbf{9}$ & The language used is well understood & 4.14 \\
\hline $\mathbf{1 0}$ & I love the anatomy learning video systema digestorium & 4.09 \\
\hline $\mathbf{1 1}$ & Anatomy learning video systema digestorium makes me the spirit of learning & 3.79 \\
\hline $\mathbf{1 2}$ & Systema digestorium anatomy learning video helps me understand anatomical \\
\hline $\mathbf{1 3}$ & material & 4.08 \\
\hline $\mathbf{1 5}$ & Anatomical video material systema digestorium in accordance with the material & 4.55 \\
\hline & Anatomical material systema digestorium heavy for new students like me & 3.57 \\
\hline
\end{tabular}

\section{DISCUSSIONS}

Score mean refers to the average value of each question based on the respondents' answers. On the overall average score, it can be seen that the value is 4.12 indicating that the respondents were quite satisfied with the videos.

From the first two questions students stated that the students had difficulty learning anatomy at home during the pandemic conditions (4.30) and they were eager to study anatomy directly in the laboratory (4.69). At points 3-9 students stated that they were satisfied with the quality of the video both in terms of the image and the sound (mean score > 4.00). The anatomical structure in question is clearly visible and the language used is also easy to understand (mean score > 4.00). The use of anatomy video as a learning medium can also increase the motivation of students in learning anatomy and help them in understanding the anatomical material of the digestive system in accordance with the existing curriculum. The results of this study are in accordance with previous research that the use of video can be an alternative media of learning anatomy, improving learning time and satisfaction in learning anatomy[5][8][9]. Similarly, videos uploaded on Youtube increase students' chances of learning anatomy[10].

Video is multimedia that conveys information through two simultaneous sensory channels, visual and auditory. Video has the advantage in supporting students to learn a subject by stimulating students to create their own imagination. Visualizations in the videos help students to expand their concept in their mind on material displayed on the screen. The use of meaningful video image in learning may be most appropriate for introductory courses or class of anatomy[11]. However, this video is also still a weakness because there are some anatomical terms that are still strange to students so that students still feel difficulty learning anatomy at the early year of medical study.

Thus, this is a seminal moment for faculty to contribute towards transformation of anatomy education by developing active curricular innovations using technology for pandemic condition and future. COVID19 pandemic has disrupted anatomy learning by face-toface lectures and laboratory teaching with cadavers, so it is a must to develop innovations in teaching anatomy. 
These changes support a transition towards distance and blended learning approaches and a learner-oriented anatomy curriculum using technology enhancement learning (TEL) [12].

\section{CONCLUSIONS}

The results show that video anatomy of digestive system are very likely to be developed in the anatomy laboratory and these videos are appropriate materials for an alternative educational media in teaching and learning anatomy of digestive system in pandemic era and future. The videos help students in learning anatomy and students feel satisfied with the videos.

\section{ACKNOWLEDGMENTS}

We would like to thank those who have been involved and helped in completing the video especially Reza and team, anatomy laboratory assistant and our students for this study.

\section{REFERENCES}

[1] K. Kelly, L. R. Y. Hwei, and G. S. Octavius, "Coronavirus outbreaks including COVID-19 and impacts on medical education: a systematic review," J. Community Empower. Heal., 2020, vol. 3, no.2, p. 130, doi: 10.22146/jcoemph.57082.

[2] A. Singal, Agam Bansal, · Priti Chaudhary, · Harsimranjit Singh, and · Apurba Patra, "Anatomy education of medical and dental students during COVID-19.pdf," Surg. Radiol. Anat., 2020, /doi.org/10.1007/s00276-02002615-3.

[3] R. Hilburg, N. Patel, S. Ambruso, M. A. Biewald, and S. S. Farouk, "Medical Education During the Coronavirus Disease-2019 Pandemic: Learning From a Distance," Adv. Chronic Kidney Dis., 2020, vol. 27, no. 5, pp. 412-417, doi: 10.1053/j.ackd.2020.05.017.

[4] A. Alsoufi et al., "Impact of the COVID-19 pandemic on medical education: Medical students' knowledge, attitudes, and practices regarding electronic learning," PLoS One, 2020 vol. 15, no. 11 November, pp. 1-20, doi: 10.1371/journal.pone.0242905.

[5] J. Iwanaga, A. S. Dumont, and R. S. Tubbs, "A review of anatomy education during and after the COVID-19 pandemic : Revisiting traditional and modern methods to achieve future innovation," Clinical Anatomy, 2020, no. July, pp. 1-7, , doi: 10.1002/ca.23655.

[6] Wiyono, N and Hastami, Y., "Alternatif Metode Pembelajaran Anatomi Kedokteran," Anat. Med. J., 2018. vol. 1, no. 2, pp. 68-77,

[7] A. Hulme and G. Strkalj, "Videos in Anatomy
Education: History, Present Usage and Future Prospects,” Int. J. Morphol, 2017, vol. 35, no. 4, pp. 1540-1546

[8] Jaffar, A.A "YouTube: An Emerging Tool in Anatomy Education," Anatomy Sci Educ, 2012, vol. 164, no. June, pp. 158-164, doi: 10.1002/ase.1268.

[9] T. Christ, P. Arya, and M. M. Chiu, "Video use in teacher education: An international survey of practices," Teach. Teach. Educ., 2017, vol. 63, pp. 22-35, doi: 10.1016/j.tate.2016.12.005.

[10] A. G. Mustafa, N. R. Taha, O. A. Alshboul, M. Alsalem, and M. I. Malki, "Using YouTube to Learn Anatomy: Perspectives of Jordanian Medical Students," Biomed Res Int, 2020, pp 18

[11] N. Fajar Masyitoh, N. Malihah, F. Risdianto, and A. Guritno, "Video as Educational Multimedia to Teach English Speaking," J. Phys. Conf. Ser., 2019, vol. 1339, no. 1, doi: 10.1088/17426596/1339/1/012118.

[12] K. Singh, U. Gaur, K. Hall, K. Mascoll, D. Cohall, and M. Azim Majumder, "Teaching anatomy and dissection in an era of social distancing and remote learning," Adv. Hum. Biol., 2020, vol. 10, no. 3, p. 90, doi: 10.4103/aihb.aihb_87_20. 